\title{
Bent-shaped liquid crystal dimers. Influence of the direction of the oxybiphenylenecarboxyl groups on their mesomorphic behavior
}

\author{
Claudia M. Hegguilustoy, Rosana S. Montani, María B. Darda, \\ Pablo G. Del Rosso, and Raúl O. Garay* \\ INQUISUR, Departamento de Química, Universidad Nacional del Sur, Alem 1253, \\ 8000 Bahía Blanca, Argentina \\ E-mail:rgaray@criba.edu.ar
}

\section{Dedicated to Professors Oscar S. Giordano, Manuel González Sierra, Julio C. Podestá and Rita H. de Rossi}

\begin{abstract}
In order to study what role the direction of the whole mesogenic groups play on their mesomorphic behavior we synthesized a series of bent-shaped dimers in which the mesogens differ in their relative orientation along the long molecular axis of the dimers. A tilted anticlinic smectic mesophase is presented exclusively by the dimer where the mesogens are tethered in a head-to-head fashion. The head-to-tail and tail-to-tail organizations of the mesogens preclude any kind of mesophase formation. The mesomorphic behavior of dimers was characterized by a combination of polarizing optical microscopy, differential scanning calorimetry and computational techniques.
\end{abstract}

Keywords: Liquid crystal, symmetric dimers, synthesis, mesomorphism

\section{Introduction}

Two rigid mesogenic units connected by a conformationally flexible spacer constitutes a liquid crystal dimer (LCD) whose mesomorphic behavior manifests unique liquid crystal characteristics or resembles that observed in polymeric systems. ${ }^{1,2}$ The liquid crystalline properties of LCDs include a strong dependence of their transitional properties on the length and parity of aliphatic spacers. $^{3-5}$ These methylene chains are considered mostly extended in an all-trans conformation within the mesophases. ${ }^{4}$ Thus, as shown in Figure 1a, dimers with even-membered spacers are attributed zigzag molecular shapes with the long molecular axis of the mesogens oriented parallel to the longitudinal molecular axis. In contrast, odd-membered dimers are considered to have bent molecular shapes with the long molecular axis of the mesogens inclined with respect 
to the longitudinal axis of the dimer (Figure 1b). Until now a great number of dimeric mesogens have been synthesized and characterized. ${ }^{1,2,6-8}$ Evidently, the mesogenic behavior depends much more on structural variations of dimers in comparison with monomeric calamitic compounds. Normally the mesophase behavior is influenced by the length and structure of the mesogenic units, the nature and length of the spacer and terminal chains, the existence of lateral groups and by the structure, position and direction of the linking groups. The last structural change has hardly been explored. ${ }^{9,10}$

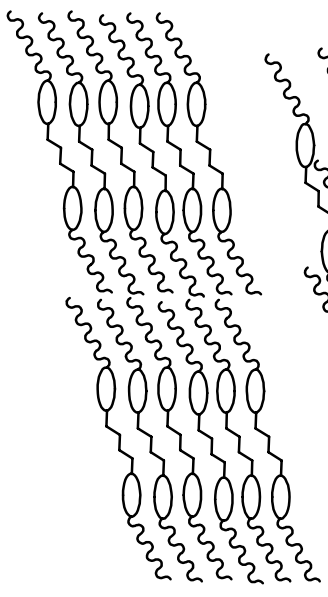

(a1)

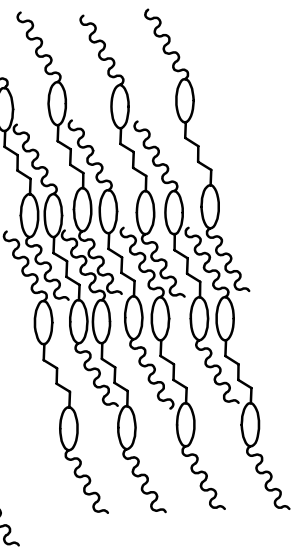

(a2)

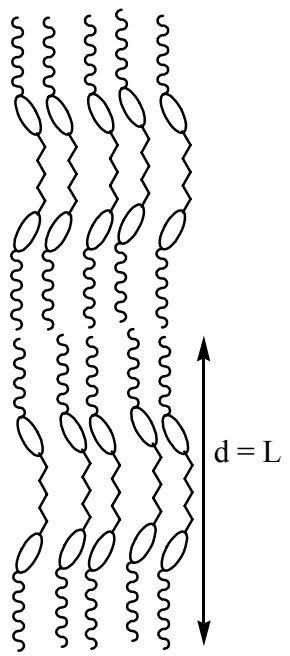

(b1)

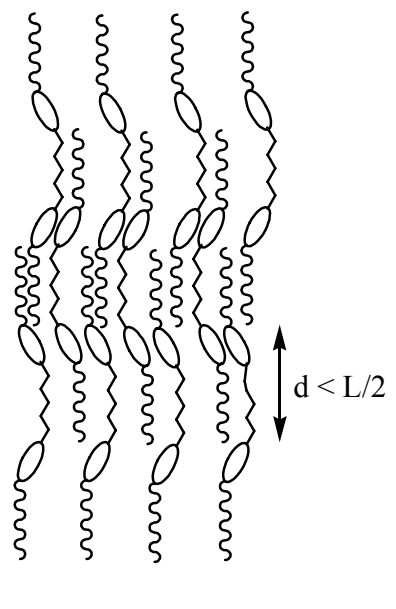

(b2)

Figure 1. Schematic representations of mesophases. (a1) Single layer and (a2) intercalated untilted smectic A phases composed of even-membered dimers. (b1) Single layer, layer spacing equals the molecular length $\mathrm{L}$ and (b2) intercalated tilted anticlinic smectic $\mathrm{C}_{\mathrm{A}}$ phases composed of odd-membered dimers.

Our aim was to study what role the direction of the whole mesogenic groups play on the mesomorphic behavior of dimers with biphenylene rigid units. ${ }^{11}$ We synthesized a series of structurally related bent-shaped dimers in which both oxybiphenylenecarboxyl groups differ in their relative orientation along the long molecular axis of the dimer. The bent dimers have symmetric two-block molecular architectures with alternating non-polar aliphatic chains and rigid biphenylenes that are favorable for the generation of lamellar phases. They posses mesogen arrangements that may be regarded as built up from $4^{\prime}$-oxybiphenylene-4-carboxyl units linked either "head to head" as in 6D5-hh; that is, both carboxylic groups are linked by a fivemembered spacer and bear six-membered terminal chains (see Scheme 1), or "head to tail" in 6D6-ht, or "tail to tail" in 6D5-tt and 4D5-tt. A spacer with six methylene groups instead of five was used in 6D6-ht to compensate the lack of a carbonyl group in one of the linking groups and hence to retain the bent nature of the dimer structure. 


\section{Results and Discussion}

The synthesis of the monomeric 6M5, bent dimers 6D5-hh, 6D6-ht, 6D5-tt, 4D5-tt and trimer 6T6-ht is outlined in Scheme 1. The synthetic routes involve standard alkylation and esterificacion reactions. It is noteworthy that a small amount of the $\omega$-hydroxylated dimeric $\mathbf{2 b}$, that is, the product of the self-transesterification of $\mathbf{2 a}$, was unexpectedly formed during the synthesis of $\mathbf{2 a}$, possibly as a result of excess reflux time. Thus, we were able to obtain the trimer 6T6-ht by a relatively short route. Overall, emphasis was placed on purity rather than yield since it is known that presence of minute quantities of residual solvent or impurities significantly affect the thermal behavior of mesogenic compounds. ${ }^{12}$ Thus, all final esters were recrystallized at least three times even though their ${ }^{1} \mathrm{H}$ NMR spectra corresponded to a pure substance and were thoroughly dried under vacuum.

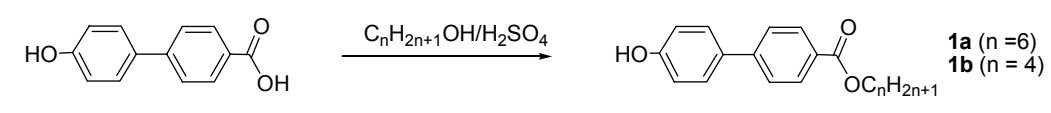

$1 \mathrm{a}$
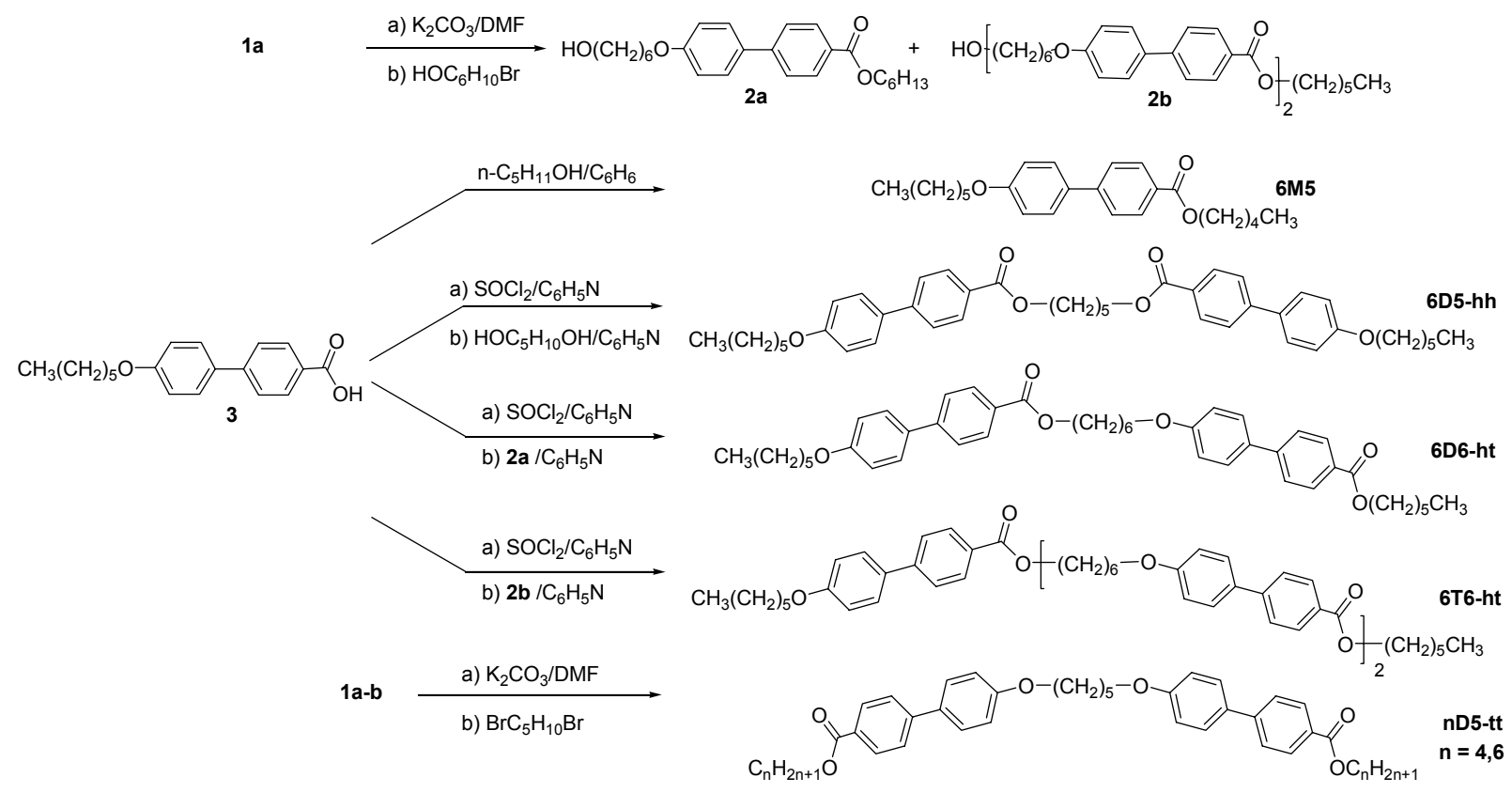

Scheme 1. Synthesis of the alkoxybiphenylenecarboxylic esters.

The phase transition behavior of compounds was investigated using differential scanning calorimetry (DSC) and polarizing optical microscopy (POM) methods. Transition temperatures and associated enthalpies obtained from DSC thermograms of esters observed at cooling rates of $5{ }^{\circ} \mathrm{C} / \mathrm{min}$ are shown in Table 1. 
Table 1. Phase sequence, phase transition temperatures, enthalpies and entropies changes of the alkoxybiphenylenecarboxylic esters ${ }^{\mathrm{a}}$

\begin{tabular}{ll}
\hline & Phase transitions sequence, transition temperatures $/{ }^{\circ} \mathrm{C}\left[\Delta \mathrm{H}\left(\mathrm{kJ} \mathrm{mol}^{-1}\right) ; \Delta \mathrm{S} / \mathrm{R}\right]$ \\
\hline 6M5 & $\mathrm{Cr} 74[21.3,7.4] \mathrm{SmA} 88[9.10,3.0] \mathrm{I}$ \\
6D5-hh & $\mathrm{CrE} 107[13.9,4.4] \mathrm{SmC}_{\mathrm{A}} 136[23.2,6.9] \mathrm{I}$ \\
6D6-ht & $\mathrm{CrX} 94[12.9,4.2] \mathrm{CrB} 116[59.8,18.5] \mathrm{I}$ \\
6T6-ht & $\mathrm{CrX} 114[2.8,0.9] \mathrm{CrB} 125[28.5,8.6] \mathrm{I}$ \\
6D5-tt & $\mathrm{Cr} 109[58.7,18.5] \mathrm{I}$ \\
4D5-tt & $\mathrm{Cr} 106[41.9,13.3] \mathrm{I}$ \\
\hline
\end{tabular}

${ }^{a}$ Recorded in the first cooling cycle.

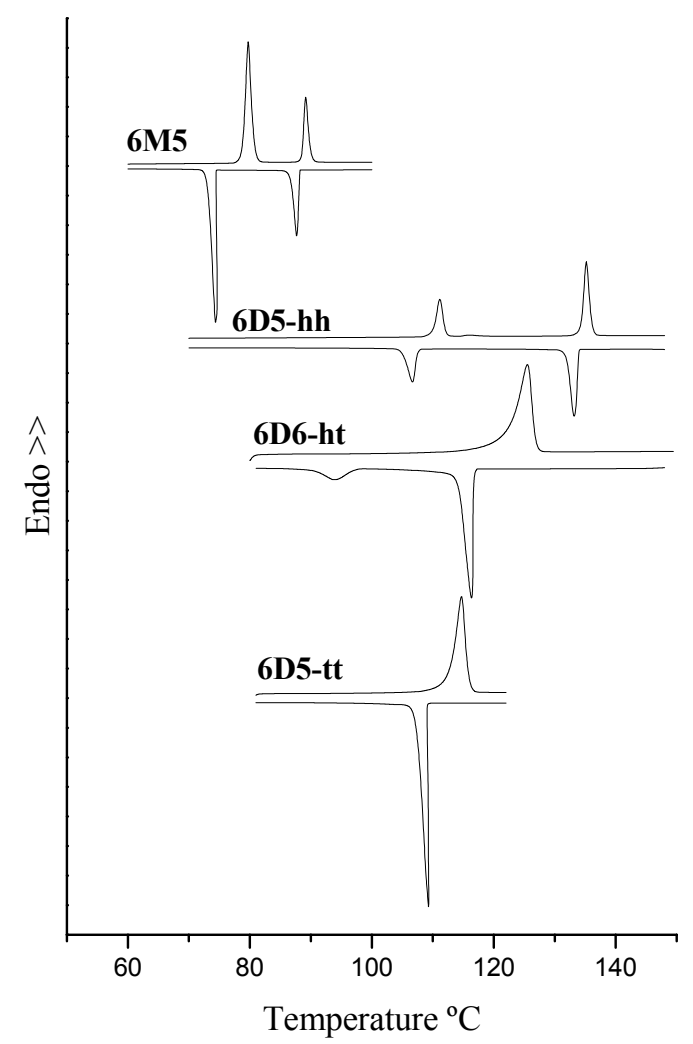

Figure 2. DSC termograms of first cooling and second heating cycles.

Figure 2 shows a set of DSC diagrams for the first cooling (1C) and subsequent second heating cycles $(2 \mathrm{H})$ for the 6D5-hh, 6D6-ht and 6D5-tt dimers as well as those corresponding to the monomeric 6M5 and the 6T6-ht trimer. In this set of DSC diagrams, a quite distinct thermal behavior for the three dimers is evident. However, most compounds share an enantiotropic behavior, i.e.: the exothermic phase transitions processes observed during cooling are mirrored in the subsequent heating cycle by endothermic processes that reversed those phase transitions that 
occurred during cooling; the exception being dimer 6D6-ht which shows an additional exothermic transition in the cooling cycle.

The DSC thermogram of 6D5-hh shows two first-order phase transitions in both heating and cooling cycles with rather large enthalpy changes indicating that appreciable molecular reorganization takes place at these two temperatures. The enthalpy change associated to the last transition at $136{ }^{\circ} \mathrm{C}$ is too large to be ascribed to a transition from a low-order nematic phase to the isotropic phase. It could instead correspond to an isotropization process from a more ordered mesophase. Indeed, POM observations of thin samples of 6D5-hh that were prepared by melting a minimum amount of compound between a clean glass slide and a cover slip, clearly showed that on cooling the isotropic liquid a mesophase was formed that exhibited a broken fan-shaped texture with a few small schlieren areas (Figure 3a). In fact, it is expected from its bent dimer structure that 6D5-hh would tend to form tilted SmC phases which appear as typical fan-shaped or as schlieren textures. Further cooling resulted in a transition to a phase which exhibited a paramorphotic focal-conic fan texture with concentric arcs (Figure 3b). The appearance of these permanent arcs is a signature of the untilted soft crystal E phase. Observations that confirmed these mesophase observations were done using DTS-treated glass substrates. These aliphatic surfaces promote the formation of planar smectic organizations where the smectic layers are parallel to the glass surface. In this case, they favor the formation of the planar schlieren textures over the focal conic fan textures. Thus, a schlieren texture which covers all the optical field was formed (Figure 3c). The texture exhibits at $132{ }^{\circ} \mathrm{C}$ not only singularities with four brushes $(s=$ \pm 1 ) which are typical for a synclinic SmC texture, but in addition, many singularities with two brushes $(s= \pm 1 / 2)$ occur which have been observed in intercalated phases of smectogenic dimers. ${ }^{13,14}$ In anticlinic $\mathrm{SmC}_{\mathrm{A}}$ phases, the manifestation of such singularities is the result of an opposite tilt direction of the mesogenic groups between adjacent layers. ${ }^{15,16}$ On further cooling, the soft crystal $\mathrm{E}$ phase shows another of its characteristic textures, i.e., the schlieren texture of the $\mathrm{SmC}_{\mathrm{A}}$ phase changed to a 'scale'-like mosaic texture (Figure 3d). On the other hand, the monomeric 6M5 shows only an untilted SmA phase. Optical microscopy revealed that a typical smectic A phase, which exhibited typical focal-conic fan and homeotropic textures, was formed from the isotropic liquid on cooling. Further cooling produced a crystalline phase.

On the contrary, the DSC thermogram of 6D5-tt shows only one transition in both heating and cooling cycles indicative of the absence of liquid crystallinity. Moreover, on cooling the isotropic liquid a highly birefringent spherulitic growth typical of crystal-to-isotropic transitions was observed by POM. Finally, no evidence of liquid crystalline behavior was gathered from the thermal and optical studies of the head-to-tail dimer 6D6-ht as well as from the trimer 6T6-ht. The DSC diagrams of 6D6-ht show two types of phase transitions in the cooling cycle. The first transition has a rather small enthalpy change but the one associated to the last broad transition in the heating cycle at $126^{\circ} \mathrm{C}$ is large and showed an undercooling effect. POM observations indicated that the isotropization process occurs at $116^{\circ} \mathrm{C}$. Surprisingly, very little birefringence emerged from the black isotropic melt on cooling, though the sample turned out not to be fluid. The texture appeared to be composed of a few dots and thin bright rods on a black field 
representative of a homeotropic alignment of the mesogens. On further cooling, only a small increase in the birefringence was observed at $94{ }^{\circ} \mathrm{C}$. Observations carried out using DTS-treated glass substrates gave similar results. In order to clarify the nature of the transition to the isotropic state, cooling and subsequent heating rates of $2.5,5,10$ and $20{ }^{\circ} \mathrm{C} / \mathrm{min}$ were used to record the DSC traces of dimers 6D5-hh, 6D6-ht and 6D5-tt. While the liquid crystalline 6D5-hh showed a small undercooling of $c a .2-3{ }^{\circ} \mathrm{C}$ in the last transition as it is expected for a mesophase-toisotropic transition, an evident cooling-rate dependence of $c a .7-11{ }^{\circ} \mathrm{C}$, which is typical of crystal-to-isotropic transitions, was found for the crystalline 6D5-tt and as well as for 6D6-ht. Therefore, the optically uniaxial solid phase of 6D6-ht most probably has a soft crystal B organization. A thermal behavior similar to that observed for the dimer 6D6-ht and evidence of the presence of an optically axial phase was gathered for the trimer 6T6-ht.

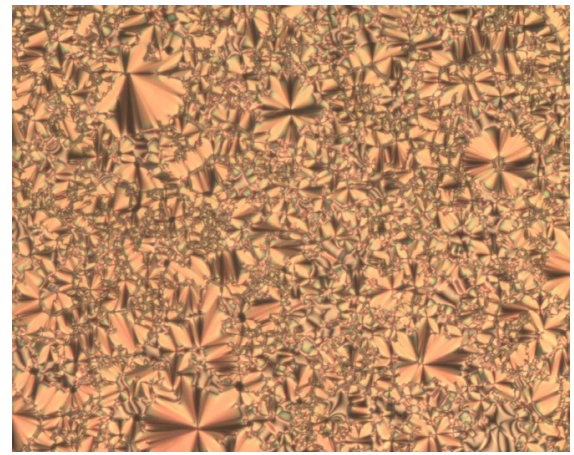

(a)

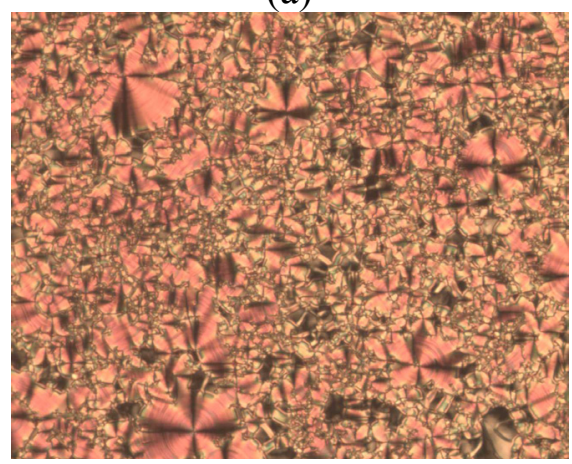

(b)

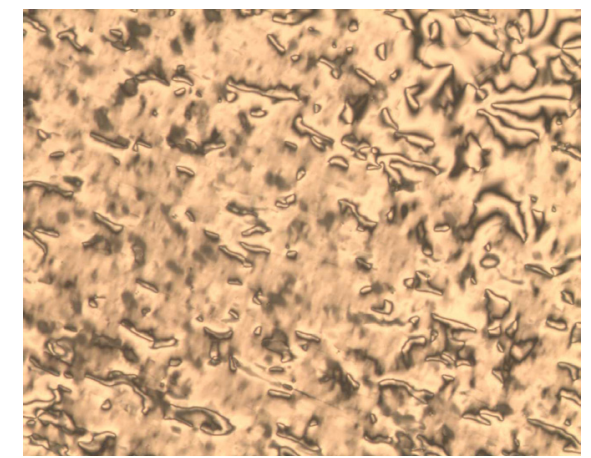

(c)

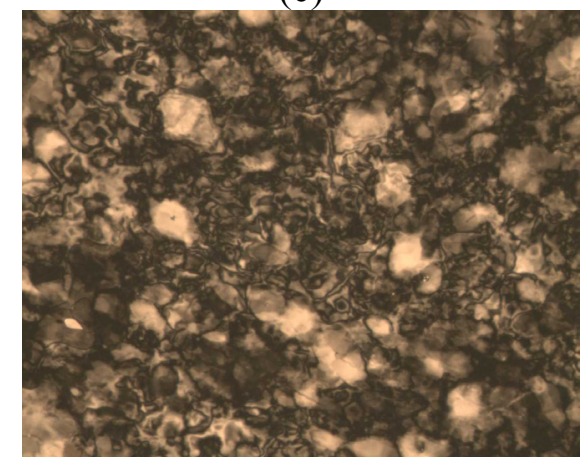

(d)

Figure 3. Optical micrographs of 6D5-hh. Virgin glass substrate, a) $134{ }^{\circ} \mathrm{C}$ and b) $96{ }^{\circ} \mathrm{C}$. (DTS)-coated glass substrate, c) $132{ }^{\circ} \mathrm{C}$ and d) $106{ }^{\circ} \mathrm{C}$.

Thus, we found that the tail-to-tail organization of the mesogens in 6D5-tt precludes any kind of mesophase formation. Moreover, the shorter tail-to-tail dimer 4D5-tt was prepared to test whether the absence of mesomorphism in 6D5-tt could be due to a mismatch between the length of the pentylene spacer and hexyloxy terminal chains. Indeed, similar thermal and optical behaviors were observed for both tail-to-tail dimers, thus indicating that the length of terminal chains plays no role in their lack of liquid crystallinity. Similarly, the head-to-tail organization of 
the mesogens in 6D6-ht is not conducive to the formation of fluid mesophases. POM observations and DSC traces indicated that only optically uniaxial soft crystalline phases of the B type were present in dimer 6D6-ht, the related hydroxylated compound $\mathbf{2 b}$, and trimer 6T6-ht. A previous study ${ }^{17}$ reports that poly(hexyleneoxybiphenylenecarboxy) exhibited a fluid tilted mesophase $\mathrm{SmC}_{\mathrm{A}}$, thus suggesting that stabilization of a smectic phase in the head-to-tail organization can only be achieved by the polymeric state.

Indeed, it is apparent that a fluid smectic mesophase is presented exclusively by the dimer where the oxybiphenylenecarboxyl mesogens are tethered in the head-to-head fashion. This mesophase is the anticlinic tilted $\mathrm{SmC}_{\mathrm{A}}$ although its monomeric precursor $\mathbf{6 M 5}$ forms an untilted SmA phase. The increase in $\mathrm{T}_{\mathrm{SI}}$ on passing from $6 \mathrm{M5}$ to the dimer 6D5-hh evidences that the mesogenic units in the dimer are much more correlated than in the monomeric compound given the enhanced shape anisotropy of the dimer (see Figure 4); likewise the two-fold increase in $\Delta S_{\mathrm{SI}} / R$ demonstrates a significant increment in the orientational order of the mesogenic groups (see Table 1).

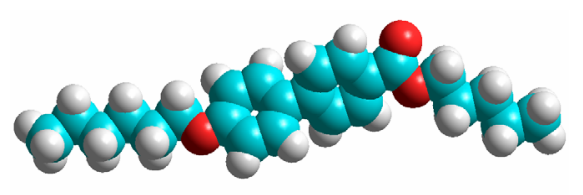

a) $\mathrm{R}=3.2$

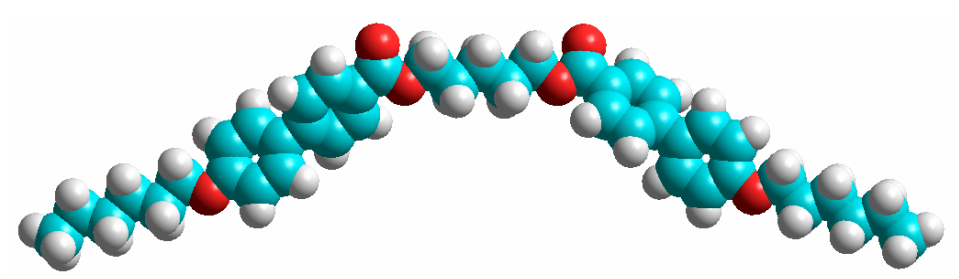

b) $\mathrm{R}=3.6$

Figure 4. RM1 gas-phase structures of a) 6M5 and b) 6D5-hh. The aspect ratio R = L/D was calculated considering the molecular length, L, and the largest diameter, D, found along the molecular inertial axes.

However, the inherent collective nature of the lamellar organization could be rather susceptible to small perturbations. Thus, the stability of the smectic mesophase was tested through the mesomorphic behavior of $\mathbf{6 D 5}-\mathbf{h h} / \mathbf{6 M 5}$ binary mixtures whose phase diagram is shown in Figure 5. The mixing of the bent dimer and the linear monomeric compound does not originate a less ordered nematic phase to the detriment of the smectic phases. Moreover, although this phase diagram does not show continuous miscibility across the full composition range, it does show an overall stabilization of the smectic phases and, in particular, a stabilization of the SmA at the cost of the SmC phase. Analogous results have been observed in binary mixtures of chemically similar compounds which carry a single smectogen but have widely different molecular lengths and had been attributed to the avoidance of free volume by out-oflayer fluctuations. ${ }^{18,19}$ Here, we first observed that the tilted $\mathrm{SmC}_{\mathrm{A}}$ phase is stable in mixtures with up to $\sim 20 \%$ weight fraction of the linear 6M5. The tilted and untilted mesophases then coexist in the $\sim 20 \%-\sim 30 \%$ range and finally the SmA is the only low ordered smectic phase present on increasing concentration of the short smectogen. In addition, an injected SmB 
mesophase not present in either smectogen appeared below the entire SmA range. Possibly, the anticlinic interlock of the bent dimer is destroyed after the addition of $c a .20 \%$ weight fraction of the linear compound by increased out-of-layer fluctuations that led to an untilted orientation of the mesogens in the SmA and SmB phases.

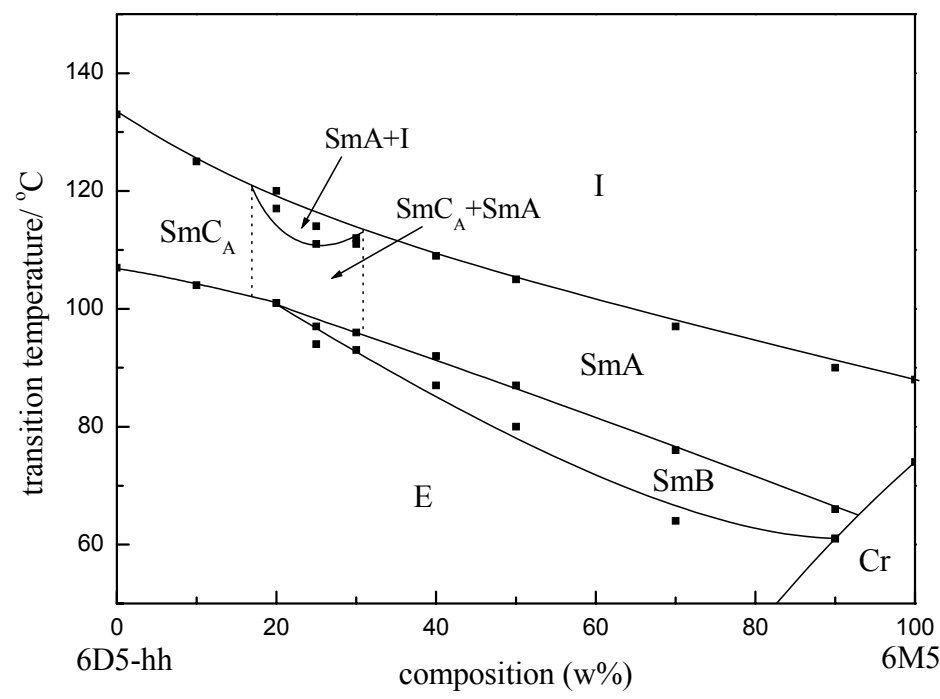

Figure 5. The composition-temperature phase diagram for the binary system with compounds 6D5-hh and 6M5. The dotted lines were added as a visual aid to circumscribe the region of nonmiscibility.

In summary, the highest clearing temperature and mesomorphism is observed for the dimer having two inner polar carboxyl groups but increasingly lower isotropization temperatures and higher tendency to crystalline order occur when the carboxyl groups move out from these positions to the periphery of the mesogenic groups.

\section{Experimental Section}

General. 4'-hydroxybiphenyl-4-carboxylic acid was a gift from Nippon Steel Chemical Ltd.. All other reagents and solvents were purchased from Aldrich and used without further purification unless otherwise specified. Melting points reported are not corrected. ${ }^{1} \mathrm{H}$ NMR and ${ }^{13} \mathrm{C}$ NMR spectra were recorded on a Bruker ARX300 spectrometer at $25^{\circ} \mathrm{C}$.

The initial phase assignments and corresponding transition temperatures for the final products were determined and imaged by thermal optical microscopy using a Leitz (Model Ortholux) polarizing microscope equipped with a pair of crossed polarizers and a hot stage (Mettler). Thin samples were prepared by melting a minimum amount of compound between a clean glass slide and a cover slip, which could be virgin or dodecyltrichlorosilane (DTS)-coated. Heating and 
cooling rates varied from 0.1 to $5{ }^{\circ} \mathrm{C} \mathrm{min}^{-1}$. Temperatures and enthalpies of transitions were investigated by differential scanning calorimetry (DSC) using a TAQ20 instrument. Samples of about $5 \mathrm{mg}$ were studied under a nitrogen flow at scanning rate of $5{ }^{\circ} \mathrm{C} \mathrm{min}^{-1}$, for both heating and cooling cycles, after being encapsulated in aluminum pans. The entropy changes at the phase transition temperatures are expressed as $\Delta S / R$, in which $\Delta S$ is calculated from $\Delta S=\Delta H / T$. $\Delta H$ is calculated in $\mathrm{kJ} \mathrm{mol}^{-1}$ and $T$ is the corresponding phase transition temperature in Kelvin.

\section{Preparation of dodecyltrichlorosilane (DTS)-coated glass slides for POM observations.}

The microscope slides were cleaned in freshly prepared piranha solution $\left(70 \% \mathrm{H}_{2} \mathrm{SO}_{4}, 30 \%\right.$ $\mathrm{H}_{2} \mathrm{O}_{2}$ ) for 30 min at $80{ }^{\circ} \mathrm{C}$ using nitrogen to provide agitation, and then exhaustively rinsed with deionized water. Warning: Piranha solution should be handled with caution. It has detonated unexpectedly; likely, it has been inadvertedly mixed with significant amounts of an oxidizable organic material. Next, the slides were cleaned in base solutions $\left(70 \% \mathrm{KOH}, 30 \% \mathrm{H}_{2} \mathrm{O}_{2}\right)$ for 30 min at $80{ }^{\circ} \mathrm{C}$, and then exhaustively rinsed with deionized water, ethanol and finally methanol. The clean slides were dried under a stream of nitrogen and stored overnight at $110^{\circ} \mathrm{C}$. The slides were immersed in $10 \mathrm{mM}$ solution of dodecyltrichlorosilane (DTS) in $\mathrm{CH}_{2} \mathrm{Cl}_{2}$ for $30 \mathrm{~min}$ at room temperature, rinsed with $\mathrm{CH}_{2} \mathrm{Cl}_{2}$ and dried under nitrogen.

\section{Molecular modeling}

Molecular modeling of the compounds was carried out at the semiempirical level using the RM1$\mathrm{MO}^{20}$ program implemented in the suite of programs Hyperchem (Hypercube Inc., release 8.0.4 for windows, serial \# 12-800-1501800054, 2007). Modeling was assumed to be carried out in the gas phase at $0{ }^{\circ} \mathrm{K}$. The minimization operations were performed using the conjugate gradient method and halted by setting the gradient option at $0.01 \mathrm{kcal} / \mathrm{mol}$. The lowest potential energy conformations were found by minimization of the energy function in conjunction with conformation searches around various bonds. The molecular length of the dimer was defined as the maximum distance between the centers of the terminal hydrogen atoms, plus twice the van der Waals radius of hydrogen, given as $1.20 \AA . .^{21}$

\section{Synthesis}

Hexyl 4'-hydroxybiphenyl-4-carboxylate (1a). 4'-Hydroxybiphenyl-4-carboxylic acid (2.0 g, $9.3 \mathrm{mmol})$ was stirred with n-hexanol $(20 \mathrm{ml})$ and concentrated $\mathrm{H}_{2} \mathrm{SO}_{4}(0.2 \mathrm{ml})$ under reflux for $5 \mathrm{~h}$. The reaction mixture was then washed with $3 \% \mathrm{NaHCO}_{3}(4 \times 25 \mathrm{ml})$ and water $(2 \times 25 \mathrm{ml})$. The paste was then placed under reduced pressure to remove the remaining hexanol and recrystallized from benzene. Beige powder, yield $86 \%, 2.39 \mathrm{~g}, \mathrm{mp} 93-95{ }^{\circ} \mathrm{C} .{ }^{1} \mathrm{H}$ NMR $(300$ $\left.\mathrm{MHz}, \mathrm{CDCl}_{3}\right): \delta=8.08(\mathrm{~d}, 2 \mathrm{H}, J=8.57 \mathrm{~Hz}), 7.60(\mathrm{~d}, 2 \mathrm{H}, J=8.68 \mathrm{~Hz}), 7.52(\mathrm{~d}, 2 \mathrm{H}, J=8.78$ $\mathrm{Hz}), 6.93(\mathrm{~d}, 2 \mathrm{H}, J=8.77 \mathrm{~Hz}), 5.04(\mathrm{~s}, 1 \mathrm{H}), 4.34(\mathrm{t}, 2 \mathrm{H}, J=6.67 \mathrm{~Hz}), 1.79(\mathrm{q}, 2 \mathrm{H}, J=8.77 \mathrm{~Hz})$, $1.64-1.27(\mathrm{~m}, 6 \mathrm{H}), 0.92(\mathrm{t}, 3 \mathrm{H}, J=7.04 \mathrm{~Hz}) .{ }^{13} \mathrm{C} \mathrm{NMR}\left(75 \mathrm{MHz}, \mathrm{CDCl}_{3}\right) \delta: 166.7,155.9$, $145.1,130.1,18.6,126.4,115.8,65.2,31.5,28.7,25.7,22.5,14.0$. 
Butyl 4'-hydroxybiphenyl-4-carboxylate (1b). 4'-Hydroxybiphenyl-4-carboxylic acid (2.0 g, $9.3 \mathrm{mmol})$ was stirred with n-butanol $(20 \mathrm{ml})$ and concentrated $\mathrm{H}_{2} \mathrm{SO}_{4}(0.5 \mathrm{ml})$ under reflux for $24 \mathrm{~h}$. The cooled reaction mixture was then poured into an excess of $3 \% \mathrm{NaHCO}_{3}(600 \mathrm{ml})$. The precipitated solid was then filtered off, dried under reduced pressure and recrystallized from benzene. Beige powder, yield 89\%, $2.24 \mathrm{~g}$, mp 92-94 ${ }^{\circ} \mathrm{C} .{ }^{1} \mathrm{H}$ NMR $\left(300 \mathrm{MHz}, \mathrm{CDCl}_{3}\right): \delta=8.08$ $(\mathrm{d}, 2 \mathrm{H}, J=8.4 \mathrm{~Hz}), 7.60(\mathrm{~d}, 2 \mathrm{H}, J=8.39 \mathrm{~Hz}), 7.51(\mathrm{~d}, 2 \mathrm{H}, J=8.58 \mathrm{~Hz}), 6.94(\mathrm{~d}, 2 \mathrm{H}, J=8.58$ $\mathrm{Hz}), 4.88(\mathrm{~s}, 1 \mathrm{H}), 4.35$ (t, 2H, $J=6.68 \mathrm{~Hz}), 1.77(\mathrm{q}, 2 \mathrm{H}, J=7.82 \mathrm{~Hz}), 1.49$ (m, 2H), $0.99(\mathrm{t}, 3 \mathrm{H}$, $J=7.44 \mathrm{~Hz}) .{ }^{13} \mathrm{C} \mathrm{NMR}\left(75 \mathrm{MHz}, \mathrm{CDCl}_{3}\right) \delta: 167.0,156.2,145.2,132.5,130.1,128.5,126.4$, $115.9,65.0,30.8,19.7,13.7$.

6-Bromohexanol. This compound was prepared according to a reported procedure. ${ }^{22}$ A mixture of 1,6-hexanediol (14.2 g, $0.12 \mathrm{~mol})$, toluene (700 ml), ligroin (30 ml ) and 48\% $\mathrm{HBr}(40,5 \mathrm{~g})$ was stirred and heated under reflux for $24 \mathrm{~h}$. The cooled mixture was filtered and the organic layer was separated and dried over $\mathrm{Na}_{2} \mathrm{SO}_{4}$. The solvent was evaporated to yield crude 6bromohexanol which was used without further purification. Pale tan liquid, yield $83 \%, 18 \mathrm{~g} .{ }^{1} \mathrm{H}$ NMR (300 MHz, $\left.\mathrm{CDCl}_{3}\right): \delta=3.65(\mathrm{t}, 2 \mathrm{H}, J=6.50 \mathrm{~Hz}), 3.41(\mathrm{t}, 2 \mathrm{H}, J=6.78 \mathrm{~Hz}), 1.87$ (q, 2H, $J$ $=6.79 \mathrm{~Hz}), 1.66-1.28(\mathrm{~m}, 6 \mathrm{H}) .{ }^{13} \mathrm{C} \mathrm{NMR}\left(75 \mathrm{MHz}, \mathrm{CDCl}_{3}\right) \delta: 62.7,33.7,32.7,32.4,27.9$, 24.9 .

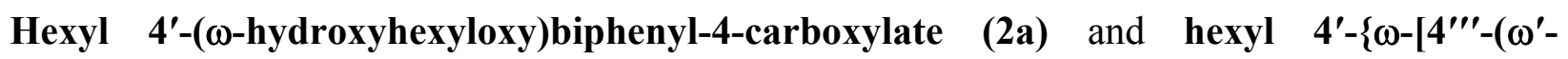
hydroxyhexyloxy)biphenylene-4"-carboxylate]hexyloxy\}biphenylene-4-carboxylate (2b). A slurry of $1 \mathrm{a}(1.5 \mathrm{~g}, 5 \mathrm{mmol})$, freshly dried $\mathrm{K}_{2} \mathrm{CO}_{3}(1.38 \mathrm{~g}, 10.0 \mathrm{mmol})$ and dry DMF (15 ml) was stirred at $120{ }^{\circ} \mathrm{C}$ for $1 \mathrm{~h}$ under $\mathrm{N}_{2}$. 6-Bromohexanol (1,09 g, $\left.6 \mathrm{mmol}\right)$ was then added dropwise over $10 \mathrm{~min}$ and the mixture was heated under reflux for $60 \mathrm{~h}$. After cooling to room temperature, the light brown mixture was poured into water $(100 \mathrm{ml})$ with stirring to precipitate the product. This was then filtered, washed with water, dried under vacuum and recrystallized from $\mathrm{EtOH}$ at room temperature.

A small amount of a beige powder was isolated by filtration and recrystallized twice from DMF to obtain a solid which turned out to be the dimeric $\mathbf{2 b}$, that is, the unexpected product of the consecutive alkylation and transesterification of 1a, yield $0.11 \mathrm{~g}, \mathrm{mp} 118-121{ }^{\circ} \mathrm{C}$. ${ }^{1} \mathrm{H} \mathrm{NMR}$ $\left(\mathrm{CDCl}_{3}\right): \delta=8.08(\mathrm{~d}, 2 \mathrm{H}, J=8.39 \mathrm{~Hz}), 7.61(\mathrm{~d}, 2 \mathrm{H}, J=8.41 \mathrm{~Hz}), 7.56(\mathrm{~d}, 2 \mathrm{H}, J=8.77 \mathrm{~Hz}), 6.98$ $(\mathrm{d}, 2 \mathrm{H}, J=8.79 \mathrm{~Hz}), 4.33(\mathrm{t}, 2 \mathrm{H}, J=6.68 \mathrm{~Hz}), 4.02(\mathrm{t}, 2 \mathrm{H}, J=6.50 \mathrm{~Hz}), 3.68(\mathrm{t}, 2 \mathrm{H}, J=6.38$ $\mathrm{Hz}), 1.91-1.70(\mathrm{~m}, 4 \mathrm{H}), 1.69-1.22(\mathrm{~m}, 14 \mathrm{H}), 0.92(\mathrm{t}, 3 \mathrm{H}, J=6.95 \mathrm{~Hz}) .{ }^{13} \mathrm{C} \mathrm{NMR}(75 \mathrm{MHz}$, $\left.\mathrm{CDCl}_{3}\right) \delta: 166.6,159.4,145.2,132.3,130.0,128.5,128.3,126.4,114.9,68.0,65.0,62.8,32.7$, $31.4,29.2,28.7,25.9,25.7,25.5,22.5,14.0$.

The ethanolic filtrate was evaporated and the residue was purified by column chromatography $\left(\mathrm{SiO}_{2}\right.$ 9:1 chloroform-methanol) afforded the hydroxyester $\mathbf{2 a}$ as a white solid, yield 43\%, mp 93 $-95{ }^{\circ} \mathrm{C} .{ }^{1} \mathrm{H}$ NMR $\left(300 \mathrm{MHz}, \mathrm{CDCl}_{3}\right): \delta=8.08(\mathrm{~d}, 2 \mathrm{H}, J=8.4 \mathrm{~Hz}), 7.61(\mathrm{~d}, 2 \mathrm{H}, J=8.4 \mathrm{~Hz}), 7.56$ $(\mathrm{d}, 2 \mathrm{H}, J=8.8 \mathrm{~Hz}), 6.98(\mathrm{~d}, 2 \mathrm{H}, J=8.8 \mathrm{~Hz}), 4.33(\mathrm{t}, 2 \mathrm{H}, J=6.7 \mathrm{~Hz}), 4.02(\mathrm{t}, 2 \mathrm{H}, J=6.5 \mathrm{~Hz})$, $3.68(\mathrm{t}, 2 \mathrm{H}, J=6.5 \mathrm{~Hz}), 1.90-1.72(\mathrm{~m}, 4 \mathrm{H}), 1.68-1.28(\mathrm{~m}, 14 \mathrm{H}), 0.92(\mathrm{t}, 3 \mathrm{H}, J=6.9 \mathrm{~Hz}) .{ }^{13} \mathrm{C}$ NMR $\left(75 \mathrm{MHz}, \mathrm{CDCl}_{3}\right) \delta: 166.6,159.4,145.2,132.4,130.0,128.7,128.3,126.4,115.0,68.0$, $65.1,62.9,32.7,31.5,29.2,28.7,25.9,25.7,25.6,22.5,14.0$. 
4'-Hexyloxybiphenyl-4-carboxylic acid (3). This compound was prepared according to a known literature procedure. ${ }^{23}$ The product was recrystallized twice from acetic acid and once from 1:2 AcOH/EtOH. White powder, yield $67 \%$, mp $268-270{ }^{\circ} \mathrm{C}$ (lit. ${ }^{21} 272.2{ }^{\circ} \mathrm{C}$ ). ${ }^{1} \mathrm{H}$ NMR $\left(300 \mathrm{MHz}, \mathrm{CDCl}_{3}\right): \delta=8.22(\mathrm{~s}, 1 \mathrm{H}) 7.85(\mathrm{~d}, 2 \mathrm{H}, J=8.02 \mathrm{~Hz}), 7.61(\mathrm{~d}, 2 \mathrm{H}, J=8.20 \mathrm{~Hz}), 7.54(\mathrm{~d}$, $2 \mathrm{H}, J=8.59 \mathrm{~Hz}), 6.91(\mathrm{~d}, 2 \mathrm{H}, J=8.58 \mathrm{~Hz}), 3.89(\mathrm{t}, 2 \mathrm{H}, J=6.49 \mathrm{~Hz}), 1.80(\mathrm{q}, 2 \mathrm{H}, J=6.87 \mathrm{~Hz})$, $1.48-1.32$ (m, 6H), $0.81(\mathrm{t}, 3 \mathrm{H}, J=7.43 \mathrm{~Hz}) .{ }^{13} \mathrm{C}$ NMR $\left(75 \mathrm{MHz}, \mathrm{CDCl}_{3}\right) \delta: 167.1,158.9$, 143.6, 131.0, 129.8, 127.9, 125.9, 114.9, 67.5, 30.8, 28.5, 25.0, 21.9, 13.7.

Pentyl 4'-hexyloxybiphenyl-4-carboxylate (6M5). Acid 3 (0.80 g, $2.7 \mathrm{mmol})$ was dissolved in an excess of n-pentanol $(20 \mathrm{ml})$ and to the mixture was added benzene $(30 \mathrm{ml})$ and concentrated sulfuric acid $(0.3 \mathrm{ml})$. The mixture was heated under reflux overnight, then the cooled reaction mixture was washed with $3 \% \mathrm{NaHCO}_{3}(2 \times 50 \mathrm{ml})$ and water $(50 \mathrm{ml})$ and dried over $\mathrm{Na}_{2} \mathrm{SO}_{4}$. The benzene solution was evaporated down until only the solution of the product in pentanol remained. To this solution hexane $(15 \mathrm{ml})$ was added and the well-stirred solution was chilled in a refrigerator overnight. The resulting precipitate was filtered off and recrystallized first from hexane and then twice from methanol. Colorless needles, yield 46\%, $0.47 \mathrm{~g} .{ }^{1} \mathrm{H}$ NMR (300 MHz, $\left.\mathrm{CDCl}_{3}\right): \delta=8.08(\mathrm{~d}, 2 \mathrm{H}, J=7.82 \mathrm{~Hz}), 7.62(\mathrm{~d}, 2 \mathrm{H}, J=7.82 \mathrm{~Hz}), 7.56(\mathrm{~d}, 2 \mathrm{H}, J=8.77 \mathrm{~Hz}), 6.98$ $(\mathrm{d}, 2 \mathrm{H}, J=8.01 \mathrm{~Hz}), 4.34(\mathrm{t}, 2 \mathrm{H}, J=6.68 \mathrm{~Hz}), 4.01(\mathrm{t}, 2 \mathrm{H}, J=6.48 \mathrm{~Hz}), 1.88-1.72(\mathrm{~m}, 4 \mathrm{H})$, $1.60-1.27(\mathrm{~m}, 10 \mathrm{H}), 1.01-0.87(\mathrm{~m}, 6 \mathrm{H}) .{ }^{13} \mathrm{C} \mathrm{NMR}\left(75 \mathrm{MHz}, \mathrm{CDCl}_{3}\right) \delta: 166.6,159.5,145.2$, 132.3, 130.0, 128.6, 128.3, 126.4, 115.0, 68.2, 65.0, 31.6, 29.2, 28.5, 28.2, 25.7, 22.6, 22.4, 14.0.Anal. Calcd for $\mathrm{C}_{24} \mathrm{H}_{32} \mathrm{O}_{3}$ (368.51): C, 78.22; H, 8.75\%, Found: C, 78.01; H, 8.80\%.

1,5-Di(4'-hexyloxybiphenyl-4-carboxylate)pentane (6D5-hh). A mixture of acid 3 (0.94 g; 3.2 mmol) and $\mathrm{SOCl}_{2}(5 \mathrm{ml})$ was heated under reflux with stirring for $4 \mathrm{~h}$. The excess $\mathrm{SOCl}_{2}$ was removed by distillation under reduced pressure and then the solid was gently warmed $\left(\sim 60^{\circ} \mathrm{C}\right)$ under vacuum $(\sim 0.5$ torr $)$ until a constant weight was reached. To this solid, a solution of 1,5pentanediol $(0.16 \mathrm{~g} ; 1.5 \mathrm{mmol})$ in dry pyridine $(8 \mathrm{~mL})$ was added and the clear solution was stirred under reflux for $24 \mathrm{~h}$. Following this, the solution was poured into $10 \% \mathrm{HCl}$ with stirring to precipitate the product. This was then filtered, dissolved into $\mathrm{CHCl}_{3}(80 \mathrm{ml})$ and the solution was stirred with $3 \% \mathrm{~K}_{2} \mathrm{CO}_{3}(3 \times 100 \mathrm{ml})$ to remove the excess carboxylic acid. The solvent was then dried over $\mathrm{Na}_{2} \mathrm{SO}_{4}$ and evaporated under reduced pressure. The remaining solid was recrystallized successively once from acetic acid and twice from acetone. White solid, yield: 0.73 g, 73\%. ${ }^{1} \mathrm{H}$ NMR $\left(300 \mathrm{MHz}, \mathrm{CDCl}_{3}\right): \delta=8.06(\mathrm{~d}, 4 \mathrm{H}, J=8.39 \mathrm{~Hz}), 7.58(\mathrm{~d}, 4 \mathrm{H}, J=8.39 \mathrm{~Hz})$, 7.52 (d, $4 \mathrm{H}, J=8.78 \mathrm{~Hz}), 6.95$ (d, $4 \mathrm{H}, J=8.78 \mathrm{~Hz}), 4.38$ (t, $4 \mathrm{H}, J=6.49 \mathrm{~Hz}), 3.99$ (t, $4 \mathrm{H}, J=$ $6.49 \mathrm{~Hz}), 1.89$ (q, $4 \mathrm{H}, J=7.82 \mathrm{~Hz}), 1.81$ (q, $4 \mathrm{H}, J=8.01 \mathrm{~Hz}), 1.55-1.30(\mathrm{~m}, 14 \mathrm{H}), 0.92$ (t, 6 $\mathrm{H}, J=6.87 \mathrm{~Hz}) .{ }^{13} \mathrm{C} \mathrm{NMR}\left(75 \mathrm{MHz}, \mathrm{CDCl}_{3}\right) \delta: 166.6,159.0,145.0,132.0,130.0,128.5,128.3$, 126.0, 115.0, 68.0, 64.6 , 31.6, 29.0, 28.4, 26.0, 22.7, 22.6, 14.0. Anal. Calcd for $\mathrm{C}_{43} \mathrm{H}_{52} \mathrm{O}_{6}$ (664.9): C, 77.68; H 7.88\%, Found: C, 77.57; H 7.97\%.

Hexyl 4'-[ $\omega-4$ "'-(hexyloxybiphenylene-4"-carboxylate)hexyloxy]biphenylene-4-carboxylate (6D6-ht). A mixture of acid 3a $(0.47 \mathrm{~g} ; 1.6 \mathrm{mmol})$ and $\mathrm{SOCl}_{2}(3.0 \mathrm{ml})$ was heated under reflux with stirring for $4 \mathrm{~h}$. The excess $\mathrm{SOCl}_{2}$ was removed by distillation under reduced pressure and then the solid was gently warmed $\left(\sim 60^{\circ} \mathrm{C}\right)$ under vacuum $(\sim 0.5$ torr $)$ until a constant weight 
was reached. To this solid, a solution of $2(0.56 \mathrm{~g} ; 1.4 \mathrm{mmol})$ in dry pyridine $(8 \mathrm{~mL})$ was added and the clear solution was stirred under reflux for $24 \mathrm{~h}$. Following this, the solution was poured into $10 \% \mathrm{HCl}$ with stirring to precipitate the product. This was then filtered, dissolved into $\mathrm{CHCl}_{3}(80 \mathrm{ml})$ and the solution was stirred with $3 \% \mathrm{~K}_{2} \mathrm{CO}_{3}(3 \times 100 \mathrm{ml})$ to remove the excess carboxylic acid. The solvent was then dried over $\mathrm{Na}_{2} \mathrm{SO}_{4}$ and evaporated under reduced pressure. The remaining solid was recrystallized successively three times from acetic acid and once from DMF. White solid, yield: $0.62 \mathrm{~g}, 65 \% .{ }^{1} \mathrm{H} \mathrm{NMR}\left(300 \mathrm{MHz}, \mathrm{CDCl}_{3}\right): \delta=8.07$ (d, $4 \mathrm{H}, J=8.4 \mathrm{~Hz}$ ), $7.61(\mathrm{~d}, 2 \mathrm{H}, J=8.4 \mathrm{~Hz}), 7.60(\mathrm{~d}, 2 \mathrm{H}, J=8.6 \mathrm{~Hz}), 7.55(\mathrm{~d}, 2 \mathrm{H}, J=8.8 \mathrm{~Hz}), 7.54(\mathrm{~d}, 2 \mathrm{H}, J=8.8$ Hz), 6.98 (d, 2H, $J=8.8 \mathrm{~Hz}), 6.97$ (d, 2H, $J=8.8 \mathrm{~Hz}), 4.37$ (t, 2H, $J=6.5 \mathrm{~Hz}), 4.33$ (t, 2H, $J=$ $6.9 \mathrm{~Hz}), 4.03(\mathrm{t}, 2 \mathrm{H}, J=6.3 \mathrm{~Hz}), 4.00(\mathrm{t}, 2 \mathrm{H}, J=6.7 \mathrm{~Hz}), 1.91-1.72(\mathrm{~m}, 8 \mathrm{H}), 1.64-1.31(\mathrm{~m}$, $16 \mathrm{H}), 0.96-0.89(\mathrm{~m}, 6 \mathrm{H}) .{ }^{13} \mathrm{C}$ NMR $\left(75 \mathrm{MHz}, \mathrm{CDCl}_{3}\right) \delta: 166.6,159.5,159.4,145.3,145.2$, 132.3, 132.2, 130.0, 128.7, 128.5, 128.3, 128.2, 126.4, 115.0, 68.2, 68.0, 65.1, 64.8, 31.6, 31.5, 29.7, 29.2, 29.1, 28.8, 28.7, 25.9, 25.8, 25.7, 22.6, 22.5, 14.0, 13.9. Calcd for $\mathrm{C}_{44} \mathrm{H}_{54} \mathrm{O}_{6}(678.9)$ : C, 77.84; H, 8.02\%, Found: C, 77.60; H, 8.19\%.

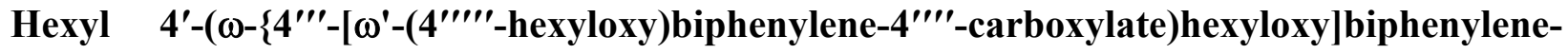
4"-carboxylate hexyloxy)biphenylene-4-carboxylate (6T6-ht). This trimer was prepared from 3b by the method described for the preparation of the dimer 6D6-ht. The solid product was recrystallized successively three times from acetic acid and once from DMF. White solid, yield: 57\%. ${ }^{1} \mathrm{H}$ NMR $\left(300 \mathrm{MHz}, \mathrm{CDCl}_{3}\right): \delta=8.07(\mathrm{~d}, 6 \mathrm{H}, J=8.4 \mathrm{~Hz}), 7.60(\mathrm{~m}, 6 \mathrm{H}), 7.54(\mathrm{~m}, 6 \mathrm{H}), 6.97$ (m, 6H), $4.42-4.29(\mathrm{~m}, 6 \mathrm{H}), 4.08-3.96(\mathrm{~m}, 6 \mathrm{H}), 1.94-1.72(\mathrm{~m}, 12 \mathrm{H}), 1.67-1.25(\mathrm{~m}, 20 \mathrm{H})$, $0.92(\mathrm{t}, 3 \mathrm{H}, J=6.7 \mathrm{~Hz}), 0.91(\mathrm{t}, 3 \mathrm{H}, J=6.9 \mathrm{~Hz}) \cdot{ }^{13} \mathrm{C} \mathrm{NMR}\left(75 \mathrm{MHz}, \mathrm{CDCl}_{3}\right) \delta: 166.6,159.5$, $159.4,145.2,132.2,130.0,128.5,128.3,126.4,115.0,68.2,68.0,65.1,64.8,31.6,31.5,29.2$, 29.1, 28.7, 25.9, 25.8, 25.7, 22.6, 22.5, 14.0. Calcd for $\mathrm{C}_{63} \mathrm{H}_{74} \mathrm{O}_{9}$ (975.26): C, 77.59; H, 7.65\%, Found: C, 77.42; H, 7.86\%.

1,5-Di(hexyl 4'-biphenylene-4-carboxylate)pentane (6D5-tt). A slurry of 1a (1.00 g, 3.35 $\mathrm{mmol})$, freshly dried $\mathrm{K}_{2} \mathrm{CO}_{3}(1.11 \mathrm{~g}, 8.0 \mathrm{mmol})$ and dry DMF $(10 \mathrm{ml})$ was stirred at $150{ }^{\circ} \mathrm{C}$ for 1 $\mathrm{h}$ under $\mathrm{N}_{2} .1,5$-dibromopentane $(0.37 \mathrm{~g}, 1.6 \mathrm{mmol})$ was then added dropwise over $10 \mathrm{~min}$ and the mixture was heated under reflux for $24 \mathrm{~h}$. After cooling to room temperature, the light brown mixture was poured into water $(150 \mathrm{ml})$ with stirring to precipitate the product. This was then filtered, dissolved into $\mathrm{CHCl}_{3}(80 \mathrm{ml})$ and the solution was stirred with $3 \% \mathrm{~K}_{2} \mathrm{CO}_{3}(3 \times 100 \mathrm{ml})$ to remove the excess carboxylic acid. The solvent was then dried over $\mathrm{Na}_{2} \mathrm{SO}_{4}$ and evaporated under reduced pressure. The remaining solid was dried under vacuum then recrystallized twice from acetic acid and once from 1:2 AcOH/EtOH. White powder, yield 53\%, $0.53 \mathrm{~g}$. ${ }^{1} \mathrm{H}$ NMR $\left(300 \mathrm{MHz}, \mathrm{CDCl}_{3}\right): \delta=8.02(\mathrm{~d}, 4 \mathrm{H}, J=8.56 \mathrm{~Hz}), 7.56(\mathrm{~d}, 4 \mathrm{H}, J=8.53 \mathrm{~Hz}), 7.51(\mathrm{~d}, 4 \mathrm{H}, J=$ $9.04 \mathrm{~Hz}), 6.94(\mathrm{~d}, 4 \mathrm{H}, J=8.93 \mathrm{~Hz}), 4.28(\mathrm{t}, 4 \mathrm{H}, J=6.66 \mathrm{~Hz}), 4.01(\mathrm{t}, 4 \mathrm{H}, J=6.30 \mathrm{~Hz}), 1.86(\mathrm{q}$, $4 \mathrm{H}, J=6.47 \mathrm{~Hz}), 1.79-1.58(\mathrm{~m}, 8 \mathrm{H}), 1.48-1.23(\mathrm{~m}, 10 \mathrm{H}), 0.86(\mathrm{t}, 6 \mathrm{H}, J=6.96 \mathrm{~Hz}) .{ }^{13} \mathrm{C} \mathrm{NMR}$ $\left(75 \mathrm{MHz}, \mathrm{CDCl}_{3}\right) \delta: 165.9,158.8,144.5,131.6,129.5,128.0,127.7,125.8,114.5,67.4,64.5$, 30.9, 28.4, 28.2, 25.1, 22.2, 22.0, 13.5. Anal. Calcd for $\mathrm{C}_{43} \mathrm{H}_{52} \mathrm{O}_{6}$ (664.9): C, 77.68; H 7.88\%, Found: C, 77.47; H 8.05\%. 
1,5-Di(butyl 4'-biphenylene-4-carboxylate)pentane (4D5-tt). This compound was prepared by the method described for the preparation of 6D5-tt. The product was recrystallized twice from acetic acid and once from 1:2 AcOH/EtOH. White powder, yield 58\%. ${ }^{1} \mathrm{H}$ NMR (300 MHz, $\left.\mathrm{CDCl}_{3}\right): \delta=8.08(\mathrm{~d}, 4 \mathrm{H}, J=8.58 \mathrm{~Hz}), 7.61(\mathrm{~d}, 4 \mathrm{H}, J=8.80 \mathrm{~Hz}), 7.56(\mathrm{~d}, 4 \mathrm{H}, J=8.72 \mathrm{~Hz}), 6.99$ $(\mathrm{d}, 4 \mathrm{H}, J=8.84 \mathrm{~Hz}), 4.35(\mathrm{t}, 4 \mathrm{H}, J=6.69 \mathrm{~Hz}), 4.06(\mathrm{t}, 4 \mathrm{H}, J=6.22 \mathrm{~Hz}), 1.92(\mathrm{q}, 4 \mathrm{H}, J=6.85$ $\mathrm{Hz}), 1.83-1.66(\mathrm{~m}, 6 \mathrm{H}), 1.50(\mathrm{sext}, 4 \mathrm{H}, J=7.41 \mathrm{~Hz}), 1.00(\mathrm{t}, 6 \mathrm{H}, J=7.34 \mathrm{~Hz}) .{ }^{13} \mathrm{C}$ NMR $(75$ $\mathrm{MHz}_{\mathrm{CDCl}}$ ) $\mathrm{C}_{\mathrm{i}}$ 166.2, 159.0, 144.8, 131.9, 129.7, 128.3, 128.0, 126.0, 114.7, 67.6, 64.4, 30.5, 28.6, 22.4, 18.9, 13.4. Anal. Calcd for $\mathrm{C}_{39} \mathrm{H}_{44} \mathrm{O}_{6}$ (608.8): C, 76.95; H, 7.29\%, Found C, 77.03; H, $7.37 \%$.

\section{Acknowledgements}

Financial support from SGCyT-UNS and SPU-MCyT is acknowledged. CMH and MBD thanks CONICET for a fellowship. PGDR is member of the research staff of CIC-PBA. ROG is member of the research staff of CONICET.

\section{References}

1. Imrie, C. T.; Peterson, P. Curr. Opin. Coll. Interface Sci. 2002, 7, 298.

2. Imrie, C. T.; Henderson, P. A. Chem. Soc. Rev. 2007, 36, 2096-2124.

3. Blatch, A. E.; Luckhurst, G. R. Liq. Cryst. 2000, 27, 775-787.

4. Luckhurst, G. R. Liq. Cryst. 2005, 32, 1335-1364.

5. Imrie, C. Liq. Cryst. 2006, 33, 1449-1454.

6. Iwan,A.; Pociecha, D.; Sikora, A.; Janeczek, H.; Wegrzyn, M. Liq. Cryst. 2010, 37, 14791492.

7. Srivastava, R. M.; Neves Filho, R. A. W.; Schneider, R.; Vieira, A. A.; Gallardo, H. Liq. Cryst. 2008, 35, 737-742.

8. Araya, K.; Dunmur, D. A.; Grossel, M. C.; Luckhurst, G. R.; Marchant-Lane, S. E.; Sugimura, A. J. Mater. Chem. 2006, 16, 4675-4689.

9. Białecka-Florjańczyk, E.; Śledzińska, I.; Górecka, E.; Przedmojski, J. Liq. Cryst. 2008, 35, 401.

10. Šepelj, M.; Lesac, A.; Baumeister, U.; Diele, S.; Bruce, D. W.; Hameršak, Z. Chem. Mater. 2006, 18, 2050.

11. Montani, R. S.; Hegguilustoy, C. M., Donnio, B., Guillon, D., Garay, R. O. Tetrahedron Lett. 2009, C65, 81.

12. Thiemann, T.; Vill, V. In Handbook of Liquid Crystals, Demus,D.; Goodby, J. W.; Gray, G. W.; Spiess, H.-W.; Vill, V. Eds.; Wiley-VCH, Weinheim; 1998, Vol. 1, ch. IV, p 107.

13. Weissflog, W.; Lischka, C. H.; Diele, S.; Pelzl, W. G. Liq. Cryst. 2000, 27, 43. 
14. Pociecha, D.; Kardas, D.; Gorecka, E.; Szydlowska, J.; Mieczkowski, J.; Guillon, D. J. Mater. Chem. 2003, 13, 34.

15. Attard, G. S.; Date, R. W.; Imrie, C. T.; Luckhurst, G. R.; Roskilly, S. J.; Seddon, J. M.; Taylor, L. Liq. Cryst. 1994, 16, 529.

16. Watanabe J.; Kinoshita, S. J. Phys. II 1995, 2, 1237.

17. Nakata, Y.; Watanabe J. J. Mater. Chem. 1994, 4, 1699.

18. Kapernaum, N.; Hartley, C. S.; Roberts, J. C.; Lemieux, R. P.; Giesselmann, F. Beilstein J. Org. Chem. 2009, 5, 65.

19. Kapernaum, N.; Hartley, C. S.; Roberts, J. C.; Schoerg, F.; Krueerke, D.; Lemieux, R. P.; Giesselmann, F. Chem. Phys. Chem. 2010, 11, 2099.

20. Stewart, J. J. P. et al. J. Comput. Chem. 2006, 27, 1101.

21. Bondi, A J. Phys. Chem. 1964, 68, 441.

22. Pajouhesh, H.; Hancock, A. J. J. Lipid Res. 1984, 25, 295.

23. Gray, G. W.; Hartley, J. B.; Jones, B. J. Chem. Soc. 1955, 1412. 